\title{
Loop-armed DNA tetrahedron nanoparticles for delivering antisense oligos into bacteria
}

\author{
Xiaoyan Xue ${ }^{1}$, Yue $\mathrm{Hu}^{1}$, Zhou Chen ${ }^{1}$, xinggang $\mathrm{Mao}^{2}$, Mingkai $\mathrm{Li}^{1}$, Zheng $\mathrm{Hou}^{1}$, Jing-ru \\ Meng $^{1}$, and Xiaoxing Luo ${ }^{1}$ \\ ${ }^{1}$ Fourth Military Medical University \\ ${ }^{2}$ Xijing Hospital
}

May 5, 2020

\begin{abstract}
Background and Purpose Antisense oligonucleotides (ASOs) based technology is considered a potential strategy against antibioticresistant bacteria; however, a major obstacle to the application of ASOs is how to deliver them into bacteria effectively. DNA tetrahedra $(\mathrm{Td})$ is an emerging carrier for delivering ASOs into eukaryotes. However, there is limited information about Td used for bacteria. In this research, we investigated the uptake features of Td and the impact of linkage modes between ASOs and Td on gene-inhibition efficiency in bacteria. Experimental Approach Different bacterial strains were incubated with Td, and the bacterial uptake efficiency of Td was measured by flow cytometry and confocal microscopy. Then we designed two types of linkages modes between Td and ASOs targeting gfp, encoding green fluorescent protein , or acpP, encoding the acyl carrier protein, and assessed the efficiency of delivery by flow cytometry and gene knockdown by RT-PCR, colony counting and confocal microscopy in E. coli. Key results Td was more likely to adhere to bacterial membranes, with moderate ability to penetrate into the bacteria. Strikingly, Lipofectamine 2000 (LP2000) in a $0.125 \mu \mathrm{L} / \mu \mathrm{g}$ ratio to Td helped Td penetrate into bacteria, but had no apparent effect on linear DNA in the same concentration. Furthermore, linkage modes between ASOs and Td influenced gene-knockdown efficiency. Looped structure of ASOs linked to one side of the Td exhibited better gene-knockdown efficiency than the overhung structure. Conclusion and Implications This study established an effective antisense delivery system based on loop-armed Td, which open opportunities for developing antisense antibiotics.
\end{abstract}

\section{Title Page}

\section{Loop-armed DNA tetrahedron nanoparticles for delivering antisense oligos into bacteria}

Yue $\mathrm{Hu}^{+}, 1$, Zhou Chen ${ }^{+,}$, Xinggang $\mathrm{Mao}^{++}{ }^{1}$, Mingkai $\mathrm{Li}^{+}$, Zheng $\mathrm{Hou}^{+}$, Jingru Meng ${ }^{+}$, Xiaoxing Luo ${ }^{+},{ }^{*}$, Xiaoyan $\mathrm{Xue}^{+, *}$

+ Department of pharmacology, Fourth Military Medical University, Xi'an, China

${ }^{++}$Department of Neurosurgery, Xijing Hospital, Fourth Military Medical University, Xi'an, China

1 These three authors contributed equally to this work.

* Corresponding author:

Xiaoyan Xue, Department of pharmacology, Fourth Military Medical University, No.169, Changle West Road, Xi'an, 710032, Shaanxi Province, People's Republic of China.

E-mail: xxy.0707@163.com;

XiaoXing Luo, Department of pharmacology, Fourth Military Medical University, No.169, Changle West Road, Xi'an, 710032, Shaanxi Province, People's Republic of China.E-mail: xxluo3@fmmu.edu.cn. 
Acknowledgements

This work was supported by the National Natural Science Foundation of China (21329501, U1532119, 21227804).

\section{Conflict of interest statement}

The authors declare no competing financial interest.

\section{Abstract : \\ Background and Purpose}

Antisense oligonucleotides (ASOs) based technology is considered a potential strategy against antibioticresistant bacteria; however, a major obstacle to the application of ASOs is how to deliver them into bacteria effectively. DNA tetrahedra (Td) is an emerging carrier for delivering ASOs into eukaryotes. However, there is limited information about $\mathrm{Td}$ used for bacteria. In this research, we investigated the uptake features of $\mathrm{Td}$ and the impact of linkage modes between ASOs and Td on gene-inhibition efficiency in bacteria.

\section{Experimental Approach}

Different bacterial strains were incubated with Td, and the bacterial uptake efficiency of Td was measured by flow cytometry and confocal microscopy. Then we designed two types of linkages modes between $\mathrm{Td}$ and ASOs targeting $g f p$, encoding green fluorescent protein, or acp $P$, encoding the acyl carrier protein, and assessed the efficiency of delivery by flow cytometry and gene knockdown by RT-PCR, colony counting and confocal microscopy in E. coli .

\section{Key results}

Td was more likely to adhere to bacterial membranes, with moderate ability to penetrate into the bacteria. Strikingly, Lipofectamine 2000 (LP2000) in a $0.125 \mu \mathrm{L} / \mu \mathrm{g}$ ratio to $\mathrm{Td}$ helped $\mathrm{Td}$ penetrate into bacteria, but had no apparent effect on linear DNA in the same concentration. Furthermore, linkage modes between ASOs and Td influenced gene-knockdown efficiency.

Looped structure of ASOs linked to one side of the Td exhibited better gene-knockdown efficiency than the overhung structure.

\section{Conclusion and Implications}

This study established an effective antisense delivery system based on loop-armed Td, which opens opportunities for developing antisense antibiotics.

Keywords : DNA tetrahedron, antisense antibiotics, nanoparticles, drug delivery system

\section{Bullet point summary :}

\section{What is already known}

DNA tetrahedron had excellent ability of delivering antisense oligonucleotides (ASOs) into eukaryotes.

\section{What this study adds}

Loop-armed DNA tetrahedron nanoparticles helped ASOs inhibit target gene in bacteria.

\section{Clinical significance}

DNA tetrahedron may open a new avenue for delivering antisense antibiotics into bacteria.

\section{Table of Contents graphic}




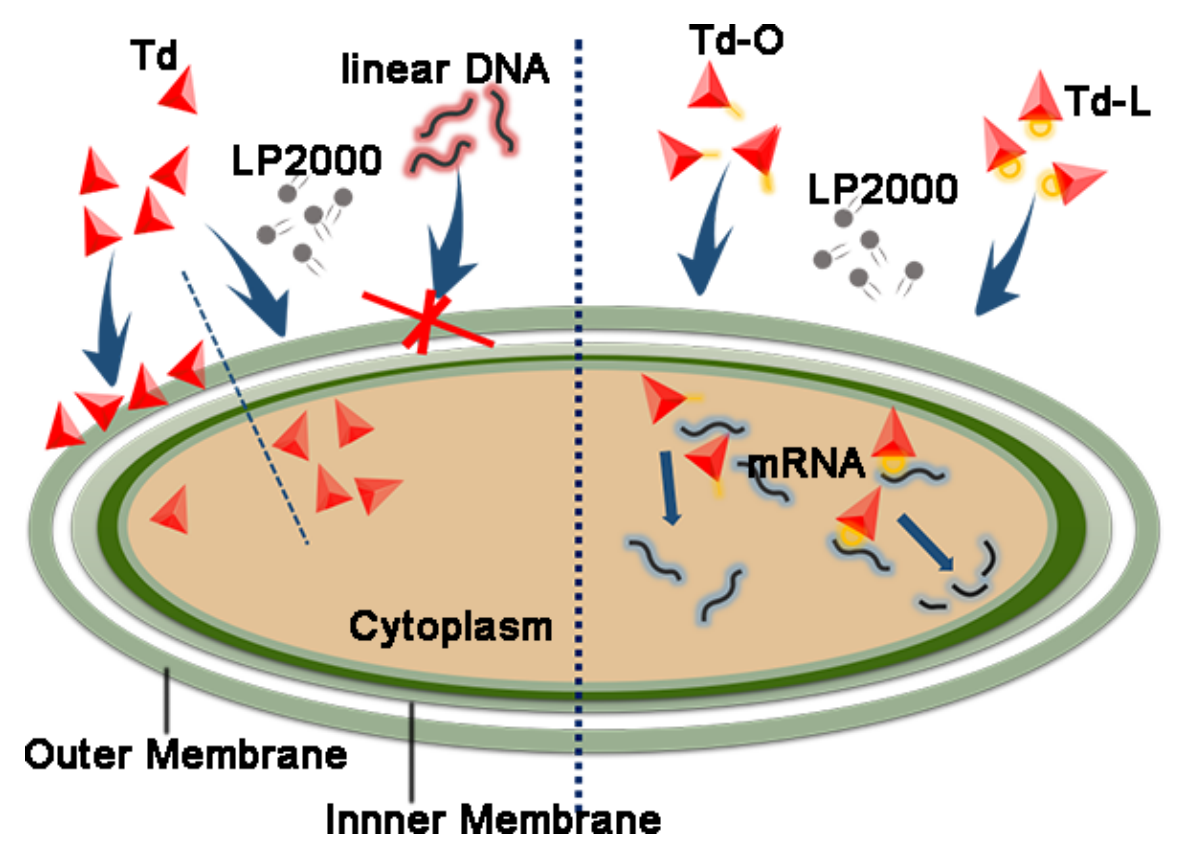

DNA tetrahedron (Td) showed apparent superiority of crossing bacterial membrane with the help of LP2000 compared with linear DNA. They were internalized by bacteria effectively when mixed with 1/16 normal concentration of LP2000. When Td was linked with antisense oligonucleotides (ASOs) as a carrier, geneknockdown efficiency of ASOs was influenced by the linkage mode between ASOs and Td, and the looped structure of ASOs linked to one side of the Td (Td-L) exhibited better gene-knockdown efficiency than the overhung structure (Td-O).

\section{Introduction}

Infections caused by antibiotic-resistant bacteria have raised public concerns worldwide. Among the assorted solutions, such as antibiotic combination(Brochado et al., 2018)and small-molecular compound screening,(Kim et al., 2018)the antisense antibacterial strategy has drawn considerable attention due to its convenient target selection, safety and decreased likelihood of inducing antibiotics resistance.(Hegarty and Stewart, 2018)By specifically blocking the expression of targeted genes in bacteria, antisense oligonucleotides (ASOs) have shown great potential to kill bacteria(Good et al., 2001)or reverse the resistance of bacteria.(Daly et al., 2017)However, without vectors, ASOs can hardly enter bacterial cells because of their high molecular weight(Frazier, 2015)and the complex structure of the bacterial cell wall,(Good et al., 2000)which are the main obstacles for ASOs in therapeutic field. Thus far, a multitude of materials have been studied for ASOs

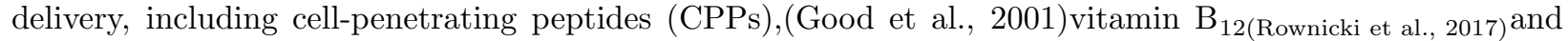
liposomes.(Meng et al., 2015)Among these materials, CPPs are the most widely used and have proven to be effective when covalently linked with ASOs, but their utilization is impeded by their cytotoxicity at high concentrations and potential immunogenicity to the host.(El-Andaloussi et al., 2007)Therefore, the development of alternative carriers is essential.

Recently, DNA nanomaterials have offered entirely new avenues for drug delivery systems.(Lee et al., 2016)Based on Watson-Crick base pairing, DNA nanoparticles exhibit excellent advantages over traditional nanoparticles, including precise manipulation of shape and size, biocompatibility, nontoxicity and increased likelihood of intelligent modification.(Linko et al., 2015)Particularly, DNA tetrahedra (Td) is widely used due to its simple preparation, rigid structure and flexible optimization.(Hu et al., 2017)In previous studies, it has been verified that Td can enter live HEK cells without transfection agents(Walsh et al., 2011)and deliver small-molecule compounds(Kim et al., 2013)or nucleic acid drugs(Lee et al., 2012)into eukaryotic cells. Furthermore, Td has great flexibility for structural modification by aptamers,(Charoenphol and Bermudez, 
2014)folate acids(Lee et al., 2012)or tumor-penetrating peptides,(Xia et al., 2016)exhibiting considerable potential for facilitating versatile drug delivery.

Nevertheless, only a few studies have focused on the application of Td as a delivery system for antibacterial agents. Leong reported that Td intercalated with actinomycin D could be internalized efficiently byEscherichia coli (E. coli) and Staphylococcus aureus (S. aureus) and showed stronger antibiotic effects than free actinomycin D in vitro.(Setyawati et al., 2014)Other studies demonstrated that Td incorporated with peptide nucleic acids targetingbla ${ }_{\text {CTX-M-group } 1}$ in cefotaxime-resistant $E$. coli(Readman et al., 2017) or ftsZ in methicillin-resistantStaphylococcus aureus (MRSA)(Zhang et al., 2018)could enter bacteria to restore sensitivity to cefotaxime or to inhibit bacterial growth by inhibiting targeted genes. These results imply that Td could be a carrier to deliver ASOs into bacteria. However, the delivery efficiency of Td in different strains and the factors that influence Td into bacteria, as well as the type of Td structure or linkage modes with ASOs remain unclear.

In this study, we investigated the uptake characteristics and efficiency of Td by different bacterial strains, including $S$. aureus ,E. coli, Shigella flexneri (S. flexneri ),NDM1 -Klebsiella pneumoniae (K. pneumoniae), multiple-drug resistantPseudomonas aeruginosa (P. aeruginosa) andAcinetobacter baumannii (A. baumannii ). Next, we designed two types of linkages modes between Td and ASOs targeting $g f p$, encoding green fluorescent protein (GFP), or acpP , encoding the acyl carrier protein (Acp), and assessed the efficiency of delivery and gene knockdown in E. coli .

\section{Result and Discussion}

Td was prepared according to methods described previously(Goodman et al., 2005) (Figure 1a) and characterized by agarose gel, atomic force microscope (AFM) and dynamic light scattering (DLS). To verify the formation of $\mathrm{Td}$, the four strands of the $\mathrm{Td}(\mathrm{S} 1, \mathrm{~S} 2, \mathrm{~S} 3$, and S4) were added one-by-one, and the gradually formed complex presented distinct bands with slower mobility as one more strand was added, indicating the successful stepwise assembly of the Td (Figure 1b). AFM images showed that the Td exhibited an average diameter of approximately $10 \mathrm{~nm}$, and a few aggregates were observed (Figure 1c). DLS analysis revealed that the $\mathrm{Td}$ had a hydrodynamic size of $\sim 12 \mathrm{~nm}$ with a polydispersity index (PDI) of 0.3 (Figure 1d).

Then, we studied the uptake features of $\mathrm{Td}$ in different bacteria.E. coli or $S$. aureus bacterial cells were incubated with FAM-labeled Td at various concentrations $(0.1,0.5$, and $1 \mu \mathrm{M})$ for $1.5 \mathrm{~h}$, and the number of FAM-positive bacteria was analyzed by flow cytometry. As a result, the positive ratios of $E$. coli incubated with FAM-labeled $\mathrm{Td}$ at concentrations of $0.1,0.5$, and $1 \mu \mathrm{M}$ were $5 \%, 35 \%$, and $49 \%$, respectively (Figure 2a), while the corresponding positive ratios of $S$. aureus were $5 \%, 24 \%$, and $56 \%$ (Figure S1a). To determine whether the observed fluorescence signals represented the uptake of the Td into bacteria or simple adherence to the bacterial membrane, the bacterial cells were treated with DNase before flow cytometry analysis. (Walsh et al., 2011)We found that after DNase treatment, the positive ratios of both tested strains decreased to approximately $20 \%$ when treated with $1 \mu \mathrm{M}$ Td (Figure 2a and S1a). However, the positive ratios of singlestrand S1 labeled with FAM were lower than $5 \%$ in both tested bacteria whether treated with DNase or not (Figure 2a and S1a). Furthermore, confocal laser scanning microscopy (CLSM) also confirmed that the fluorescence intensity of the tested bacteria was reduced significantly after treatment with DNase (Figure 2b and S1b). Similar results were also observed in other bacterial strains, including S. flexneri, NDM1-K. pneumoniae, multiple-drug resistant P. aeruginosa and A. baumannii(Figure S2). All the data demonstrated that $\mathrm{Td}$ had a tendency to bond with the bacterial membrane and only a fraction of $\mathrm{Td}$ entered into bacterial cells successfully.

Next, Lipofectamine 2000 (LP2000) was used to improve the uptake efficiency of the Td by bacteria because of the following reasons: 1) It is the cationic reagent most commonly used to neutralize the negative charge of DNA in order to reduce the electrostatic repulsion between DNA and the cellular membrane, and 2) it can electrostatically combine with the Td.(Garcia-Chaumont et al., 2000)Therefore, we explored the uptake efficiency of Td mixed with LP2000 (LP2000/Td: 0.0025, 0.0125, 0.025, and 0.125 $\mu \mathrm{L} / \mu \mathrm{g}$ ) for initial optimization. The Td mixed with LP2000 (LP-Td) showed the same size as the Td when the LP2000/Td 
ratio was 0.0025 (Figure S3a), while larger nanoparticles were formed when the ratios were greater than 0.0025. And the size increased as the ratio increased (Figure S3b and S3c). However, when the ratio of $\mathrm{LP} 2000 / \mathrm{Td}$ was $0.125 \mu \mathrm{L} / \mu \mathrm{g}$, the formed nanoparticles exhibited homogeneous sizes of approximately 30 $\mathrm{nm}$ (Figure S3d). Then we used this ratio $(0.125 \mu \mathrm{L} / \mu \mathrm{g})$ to assemble LP-Td, and characterized it by TEM and DLS (Figure 3a and 3b). To further investigate whether LP2000 at this concentration could protect Td from enzymatic hydrolysis, structural integrity of Td and LP-Td was monitored by FRET(Walsh et al., 2011). Strand S2 and S3 were labeled with cy3 and cy5 respectively, which were close enough for energy transfer from the donor cy3 to the acceptor cy5 when Td was intact. Once Td was degraded, a donor (cy3) was separated from an acceptor (cy5), then the fluorescence intensity of cy5 decreased while that of cy3 increased. Figure 3c showed that although Td and LP-Td were both degraded in $150 \mathrm{U} / \mathrm{mL}$ DNase, LP2000 protected Td from hydrolysis when DNase was $20 \mathrm{U} / \mathrm{mL}$. This data indicated that LP-Td had higher enzyme stability than Td to some extent.

According to the results of flow cytometry and CLSM, the positive ratio in E. coliimproved gradually as an increased amount of LP2000 was added, reaching $83 \%$ when the concentration of Td was $0.5 \mu \mathrm{M}$ and the LP2000/Td ratio was $0.125 \mu \mathrm{L} / \mu \mathrm{g}$ (Figure S4a and S4b). However, increasing the LP2000/Td ratio only slightly improved the positive ratio of $\mathrm{Td}$ in $S$. aureus, reaching a peak value of only $40 \%$, even at the highest LP2000/Td ratio (Figure S4c and S4d). This result may be attributed to the existence of more peptidoglycan in Gram-positive bacteria, which hindered the interaction between LP-Td and the lipid membrane. Strikingly, bacteria treated with single-strand DNA exhibited very low positive ratios $(<10 \%)$ regardless of how much LP2000 was added in those ratios. However, because the difference of molecular weights between Td and single-strand DNA led to distinct absolute amounts of LP2000, we added the same amounts of LP2000 $(0.125 \mu \mathrm{L} / \mu \mathrm{g}$ to $1 \mu \mathrm{M}$ Td) to $1 \mu \mathrm{M}$ single-strand DNA and then incubated with $E$. coliand $S$. aureus, to eliminate this interference and further clarify the superiority of Td to enter bacteria. The positive ratios were $20 \%$ and $18 \%$ in E. coli and S. aureus, respectively (Figure S5a). Importantly, when LP2000 with a $0.125 \mu \mathrm{L} / \mu \mathrm{g}$ ratio to Td was added, DNase treatment had no influence on the ratio of FAM-positive bacteria, as demonstrated by the results of flow cytometry (Figure 4a and S6a) and CLSM image analysis (Figure 4b and S6b). Furthermore, Triton X-100 was used to disrupt LP-Td nanoparticles which may adhere to bacterial membrane, and the positive ratios did not decrease (Figure S5b). All results indicated that most of the Td crossed the membrane and entered bacteria with the help of LP2000.

Next, the influences of incubation temperature and time on the uptake efficiency of LP-Td were also investigated. As a result, the uptake efficiency did not decrease when E. coli and $S$. aureuswere treated with LP-Td at $4{ }^{\circ} \mathrm{C}$ compared to $37{ }^{\circ} \mathrm{C}$, indicating that the uptake process in bacteria was energy-independent (Figure S7a). After incubation with $0.5 \mu \mathrm{M}$ LP-Td for 10, 30, 60, $180 \mathrm{~min}$, we found that the uptake efficiencies in E. coli and $S$. aureus reached the maximum value at the first time point (10 $\mathrm{min}$ ) and remained at relatively constant values at longer incubation times, indicating that the process of LP-Td internalization in bacteria was fairly quick (less than $10 \mathrm{~min}$ ) (Figure S7b). As a transfection reagent, LP2000 is commonly used in eukaryotic cells with an LP2000/DNA ratio of 2-3 $\mu \mathrm{L} / \mu \mathrm{g}$. In the present study, much less LP2000 (with an LP2000/Td ratio of 0.125) could significantly facilitate bacterial uptake of Td; by contrast, this amount of LP2000 had no effect on the uptake of single-strand DNA. Based on these results, we speculate that in this uptake process, the unique structure of the Td increases its binding with bacterial surface, while the hydrophobicity of LP2000 increases the transmembrane ability of the Td. Therefore, LP-Td could be successfully internalized by bacteria. Furthermore, the quantity of LP2000 used here $(1 \mu \mathrm{M} \mathrm{Td} ; 0.125 \mu \mathrm{L} / \mu \mathrm{g}$ LP2000/Td ratio, corresponding to $10 \mu \mathrm{L} / \mathrm{mL}$ LP2000) exerted no toxicity on $E$. coli and $S$. aureus . In fact, E. coli could endure higher concentrations of LP2000 (Figure S8).

To investigate whether the LP-Td complex could deliver ASOs into bacteria and exert gene inhibitory effects, two different strategies were designed to link functional ASOs to the Td: 1) Td-L, in which a single strand was protruding from the side of the Td as a loop (Td-L) (with 3 additional nucleotides at the end of both linking sites to expose antisense sequences), and 2) Td-O, in which the single strand was overhanging at one vertex of the $\mathrm{Td}$ (with 7 additional nucleotides added to the end of linking site to expose antisense sequences) (Figure 5a). To improve stability, ASOs were modified by phosphorothioate. The agarose gel 
results indicated the successful formation of both structures, which exhibited distinct bands with a slightly slower mobility than Td (Figure 5b). DLS demonstrated that the sizes of Td-L and Td-O were similar to that of Td (Figure 5c) and increased to $\sim 30 \mathrm{~nm}$ when LP2000 was added (Figure S9).

Next, the gene-inhibiting effects of Td-L and Td-O carrying anti-gfp ASOs were studied in E. coli expressing GFP (GFP-E. coli ). Mismatched ASOs linked to Td (Td- $\mathrm{L}_{\text {mis }}$ and Td- $\mathrm{O}_{\text {mis }}$ ) were used as controls to confirm the specific gene-inhibiting effect. A confocal study showed that $\mathrm{Td}-\mathrm{L}_{\text {anti-gfp }}, \mathrm{Td}$ and $\mathrm{Td}-\mathrm{L}_{\text {mis }}$ at a concentration of $1 \mu \mathrm{M}$ all had no influence on the fluorescent intensity of GFP-E. coli (Figure 6a and 6b). In contrast, when treated with LP-Td- $\mathrm{L}_{\text {anti-gfp }}(1 \mu \mathrm{M})$, a $75 \%$ reduction in GFP fluorescence intensity was observed in GFP-E. coli, while LP-Td and LP-Td- $\mathrm{L}_{m i s}$ also had no effect (Figure 6a and 6b). However, unlike Td- $\mathrm{L}_{\text {anti- } g f p}$, Td- $\mathrm{O}_{\text {anti-gfp }}$ did not affect GFP fluorescence regardless of whether LP2000 was used (Figure 7a and 7b), implying the importance of the specific structure of Td-L for the gene inhibitory effect.

Then, we tested whether the observed decrease in fluorescence intensity in GFP-E. coli resulted from targeted gene inhibition. After incubating for $3 \mathrm{~h}$, bacteria were collected, and total RNA was extracted to detect the mRNA level of $g f p$. The results in Figure 6c show that when treated with LP-Td-Lanti-gfp at concentrations of 0.5 and $1 \mu \mathrm{M}$, gfp expression decreased by $41.5 \%$ and $60.5 \%$, respectively, while treatment with $0.1 \mu \mathrm{M}$ LP-Td-L $\mathrm{L}_{\text {anti-gfp }}$ did not lead to an observable decrease in $g f p$ expression. Moreover, no significant decreases ingfp mRNA level were observed in the other groups at all concentrations. In addition, Figure 7c indicates that Td-O $\mathrm{O}_{\text {anti-gfp }}$ and LP-Td-O $\mathrm{O}_{\text {anti-gfp }}$ did not inhibit the gfpexpression level, consistent with the confocal results. However, flow cytometry analysis demonstrated that the bacterial uptake efficiencies of Td-L and Td-O were comparable (Figure 5d), indicating that the loop structure in Td-L facilitated its gene inhibition activity. The loop design may help ASOs combine with RNA or increase the sensitivity of the ASOs/RNA complex to RNase. Further studies to uncover the underlying mechanisms of the antisense effect of Td-L can provide potential strategies to design more effective linkage modes between Td and ASOs.

Finally, we investigated the antibacterial activity of Td-L carrying anti- acp $P$ ASOs (Td- $\mathrm{L}_{\text {anti-acp } P}$ ). Here, acp $P$ is a gene encoding the acyl carrier protein Acp, which is critical for fatty acid biosynthesis in E. coli . As shown in Figure 8a, $0.1 \mu \mathrm{M}$ LP-Td-L $\mathrm{L}_{\text {anti- acp } P}$ did not influence the growth of $E$. coli . When the concentration was increased to $0.5 \mu \mathrm{M}$, LP-Td- $\mathrm{L}_{\text {anti-acp } P}$ significantly inhibited the growth of $E$. coli at $5 \mathrm{~h}$ after treatment, as highlighted by the reduced colony-forming units (CFU) in the LP-Td- $\mathrm{L}_{\text {anti- } a c p P}$ group compared to the other groups. Furthermore, $1 \mu \mathrm{M}$ LP-Td- $\mathrm{L}_{\text {anti- acpP }}$ exhibited inhibitory effects on bacterial growth at $3 \mathrm{~h}$ and stronger effects at $5 \mathrm{~h}$. Then, we further analyzed the mRNA level of acpP to examine whether the LP-Td- $\mathrm{L}_{\text {anti- } а с p P}$-induced bacterial inhibition was mediated by targeting acp $P$. As a result, the mRNA level of acpP was found to significantly decrease in the LP-Td- $\mathrm{L}_{\text {anti-acp } P}$ group compared to the other groups. The mRNA expression level of aсpP decreased by $23 \%$ and $43 \%$ after treatment with $0.5 \mu \mathrm{M}$ and $1 \mu \mathrm{M} \mathrm{LP}-\mathrm{Td}-\mathrm{L}_{\text {anti-acpP }}$, respectively (Figure $8 \mathrm{~b}$ ). Collectively, these results demonstrated that LP-Td- $\mathrm{L}_{\text {anti-acpP }}$ exhibited antibacterial activity via its gene inhibitory effects targeting $a c p P$ and that LP2000 played a fairly essential role in the process.

\section{Conclusion}

In this study, we investigated the uptake efficiency of DNA tetrahedron (Td) in different bacterial strains. Interestingly, the $\mathrm{Td}$ adhered to the surface of the bacterial membrane efficiently, but a few could penetrate the membrane, probably due to its hydrophilicity. However, a very low ratio of LP2000 to Td facilitated the penetration of the Td into bacteria within a few minutes in an energy-independent manner. Compared with single strand DNA, Td showed superiority of crossing bacterial membrane with the help of LP2000, the reason of which may be its characteristic structure. In addition, based on the optimized LP-Td system, the modes of ASOs linked with the Td had a significant impact on gene knockdown efficiency, with the looped structure of ASOs linked to one side of Td exhibiting excellent gene-inhibiting activity. Importantly, LP-Td- $\mathrm{L}_{\text {anti- } а с p P}$ showed gene inhibitory effects targeting the $а с p P$ gene and eventually inhibited bacterial growth. Therefore, this study provides novel insights into the uptake features of $\mathrm{Td}$ in bacteria and highlights the importance of linkage strategy between ASOs and Td. In further research, multivalent ASO-containing particles could be designed based on the superior structure of $\mathrm{Td}$ and the selectivity of ASOs linking modes, 
which will open novel opportunities for developing effective antisense delivery systems.

\section{Material and method}

\subsection{Materials}

All oligonucleotides were obtained from Sangon Biotech (China). Magnesium chloride hexahydrate was purchased from Tian Li (China). Trizma base was obtained from Sigma-Aldrich (USA). Agarose was purchased from Lonza (USA). DNase I was obtained from Solarbio (China). Lipofectamine 2000 (LP2000) was purchased from Invitrogen (USA). FM4-64 was purchased from Molecular Probes (USA). Phosphatebuffered saline (PBS) and Mueller-Hinton broth (MHB) were purchased from Boster (China) and Land Bridge (China), respectively. The PrimeScript RT Reagent Kit with DNA Eraser and Premix Taq RT-PCR System were from Takara Bio Inc (Japan). The water used in all experiments was prepared via a Millipore Milli-Q purification system with a resistivity greater than $18 \mathrm{M} \Omega \mathrm{cm}-1$.

\subsection{Methods}

\subsubsection{Assembly.}

\section{Self-assembly of $T d$.}

All single strands(S1, S2, S3,S4) in equimolar quantities were mixed in TM buffer $(12.5 \mathrm{mM}$ Tris, $5 \mathrm{mM}$ $\mathrm{MgCl}_{2}, \mathrm{pH}=7.8-8.0$ ), heated to $95{ }^{\circ} \mathrm{C}$ for 5 min with an MJ MiniTM 48-well personal thermal cycler, and then cooled rapidly on ice for at least $1 \mathrm{~h}$.

Preparation of LP-Td.

Td and LP2000 were diluted in PBS respectively, and mixed. Then the mixture was incubated for 15 min at room temperature to form the LP-Td.

\subsubsection{Characterization.}

Agarose gel electrophoresis. A 1\% (w/v) agarose gel was prepared with EtBr. A total of $5 \mu \mathrm{L}$ prepared Td mixed with loading buffer was loaded and run at $95 \mathrm{~V}$ for $35 \mathrm{~min}$. To identify the Td with ASOs, a $2 \%$ $(\mathrm{w} / \mathrm{v})$ agarose gel was used.

AFM imaging. All samples were diluted to $2.5 \mathrm{nM}$ in TM buffer (12.5 mM Tris, $5 \mathrm{mM} \mathrm{MgCl} 2$ ). Then, $10 \mu \mathrm{L}$ of $\mathrm{Td}$ was dropped onto freshly cleaved mica and incubated for 5 min to allow strong absorption onto the surface. Then, the mica was rinsed using filtered deionized water and gently dried with compressed nitrogen. Next, the samples were scanned in tapping mode on an Agilent 5500 SPM.

Dynamic light scattering. A $2 \mu \mathrm{M}$ solution of Td was prepared based on the above-mentioned protocols and then diluted to $0.2 \mu \mathrm{M}$ with ultrapure water. After passing through a $0.22 \mu \mathrm{m}$ filter, samples were analyzed by a Malvern Zetasizer Nano ZS to measure the hydrodynamic size and size distribution.

TEM. LP-Td was dropped on a grid and incubated for $4 \mathrm{~min}$, then remaining solution was absorbed by filter paper. The TEM images were obtained by JEM-2100Plus with $80 \mathrm{kV}$.

\subsubsection{Enzymatic stability experiment.}

Td was self-assembled with S1, cy5-S2, cy3-S3 and S4. Then the fluorescence of $0.2 \mu \mathrm{M}$ Td or LP-Td was measured by F-2500 FL Spectrophotometer after incubation with 0, 5, 20, $150 \mathrm{U} / \mathrm{mL}$ DNase for 15 min. The fluorescence intensity of $560 \mathrm{~nm}$ (cy3) and $665 \mathrm{~nm}$ (cy5) was recorded.

\subsubsection{Transfection of bacteria.}

FAM-labeled S1 was used for the preparation of fluorescently labeled Td. Bacteria $\left(1 \times 10^{6} \mathrm{CFU} / \mathrm{mL}\right)$ were incubated with $0.1,0.5$, or $1 \mu \mathrm{M}$ FAM-Td in PBS and then treated with $500 \mathrm{U} / \mathrm{mL}$ DNase for $15 \mathrm{~min}$. FAM-S1 was used as a control. To optimize the transfection conditions, LP2000 was mixed with Td at ratios 
of $0.0025,0.0125,0.025$, and $0.125 \mu \mathrm{L} / \mu \mathrm{g}$ before incubating with bacteria, and the optimum ratio $(0.125$ $\mu \mathrm{L} / \mu \mathrm{g})$ was used in subsequent experiments.

\subsubsection{Flow cytometry.}

The uptake efficiency of $\mathrm{Td}$ in bacteria was estimated by flow cytometry. The transfected samples were centrifuged at $6000 \mathrm{~g} / \mathrm{min}$ for $5 \mathrm{~min}$ and washed twice with PBS. After resuspending in PBS, the samples were detected with a blue laser (488 nm excitation) and a 530/30 filter in the BL1 detector by a NovoCyte ${ }^{\mathrm{TM}}$ flow cytometer.

\subsubsection{Confocal microscopy.}

Bacteria were stained with $20 \mathrm{~g} / \mathrm{mL}$ FM4-64 on ice for $1 \mathrm{~min}$, then centrifuged and resuspended in PBS again. Then, $3.5 \mu \mathrm{L}$ of sample was dropped onto a slide and dried in air. Next, $5 \mu \mathrm{L}$ of antifade mounting medium was added and covered with a coverslip. All images were obtained using an Olympus FluoView FV1000 microscope. The set wavelengths were $543 \mathrm{~nm}$ excitation for FM4-64 and $488 \mathrm{~nm}$ excitation for FAM and GFP.

\subsubsection{Cell growth assay.}

E. coli bacteria were cultured in LB medium until the early log stage, then diluted to $1 \times 10^{5} \mathrm{CFU} / \mathrm{mL}$ and treated with Td-L at $0.1,0.5$, or $1 \mu \mathrm{M}$ for 1,3 , or $5 \mathrm{~h}$. At every time point, a $10 \mu \mathrm{L}$ bacterial suspension was diluted and plated. After incubating at $37^{\circ} \mathrm{C}$ overnight, colony counts in every sample were expressed as $\mathrm{CFU} / \mathrm{ml}$.

\subsubsection{RT-PCR}

After incubation with Td, the bacteria were harvested. The total RNA of the bacteria was extracted and then reverse-transcribed using the PrimeScript RT Reagent Kit with DNA Eraser. Amplification was performed according to the following steps: denaturation at $95{ }^{\circ} \mathrm{C}$ for $5 \mathrm{~min}$ and 40 cycles of $95{ }^{\circ} \mathrm{C}$ for $10 \mathrm{~s}$ and $58{ }^{\circ} \mathrm{C}$ for $30 \mathrm{~s}$. gyrA was used as an internal control.

\subsubsection{Statistical analysis.}

The results are shown as the mean $\pm \mathrm{SD}$ from at least three independent experiments. Statistical analyses were suitably implemented in Prism 6 (GraphPad, La Jolla, CA) with one-way ANOVA. A $p$-value $<0.05$ indicated a significant difference between group means.

Acknowledgements

This work was supported by the National Natural Science Foundation of China (21329501, U1532119, 21227804).

\section{References}

BROCHADO, A. R., TELZEROW, A., BOBONIS, J., BANZHAF, M., MATEUS, A., SELKRIG, J., HUTH, E., BASSLER, S., ZAMARRENO BEAS, J., ZIETEK, M., NG, N., FOERSTER, S., EZRATY, B., PY, B., BARRAS, F., SAVITSKI, M. M., BORK, P., GOTTIG, S. \& TYPAS, A. 2018. Species-specific activity of antibacterial drug combinations. Nature, 559, 259-263.

CHAROENPHOL, P. \& BERMUDEZ, H. 2014. Aptamer-targeted DNA nanostructures for therapeutic delivery. Molecular pharmaceutics,11, 1721-5.

DAly, S. M., STURGE, C. R., FELDER-SCOTT, C. F., GELlER, B. L. \& GREENBERG, D. E. 2017. MCR-1 Inhibition with Peptide-Conjugated Phosphorodiamidate Morpholino Oligomers Restores Sensitivity to Polymyxin in Escherichia coli. Mbio, 8.

EL-ANDALOUSSI, S., JARVER, P., JOHANSSON, H. J. \& LANGEL, U. 2007. Cargo-dependent cytotoxicity and delivery efficacy of cell-penetrating peptides: a comparative study. The Biochemical journal,407, $285-92$. 
FRAZIER, K. S. 2015. Antisense Oligonucleotide Therapies: The Promise and the Challenges from a Toxicologic Pathologist's Perspective. Toxicologic Pathology, 43, 78-89.

GARCIA-CHAUMONT, C., SEKSEK, O., GRZYBOWSKA, J., BOROWSKI, E. \& BOLARD, J. 2000. Delivery systems for antisense oligonucleotides.Pharmacology $\&$ therapeutics, 87, 255-77.

GOOD, L., AWASTHI, S. K., DRYSELIUS, R., LARSSON, O. \& NIELSEN, P. E. 2001. Bactericidal antisense effects of peptide-PNA conjugates. Nature biotechnology, 19, 360-4.

GOOD, L., SANDBERG, R., LARSSON, O., NIELSEN, P. E. \& WAHLESTEDT, C. 2000. Antisense PNA effects in Escherichia coli are limited by the outer-membrane LPS layer. Microbiology (Reading, England), 146 ( Pt 10), 2665-70.

GOODMAN, R. P., SCHAAP, I. A. T., TARDIN, C. F., ERBEN, C. M., BERRY, R. M., SCHMIDT, C. F. \& TURBERFIELD, A. J. 2005. Rapid chiral assembly of rigid DNA building blocks for molecular nanofabrication. Science (New York, N Y), 310, 1661-5.

HEGARTY, J. P. \& STEWART, D. B., SR. 2018. Advances in therapeutic bacterial antisense biotechnology. Appl Microbiol Biotechnol,102, 1055-1065.

HU, Y., CHEN, Z., ZHANG, H., LI, M., HOU, Z., LUO, X. \& XUE, X. 2017. Development of DNA tetrahedron-based drug delivery system. Drug delivery, 24, 1295-1301.

KIM, K.-R., KIM, D.-R., LEE, T., YHEE, J. Y., KIM, B.-S., KWON, I. C. \& AHN, D.-R. 2013. Drug delivery by a self-assembled DNA tetrahedron for overcoming drug resistance in breast cancer cells. Chemical communications (Cambridge, England), 49, 2010-2.

KIM, W., ZHU, W., HENDRICKS, G. L., VAN TYNE, D., STEELE, A. D., KEOHANE, C. E., FRICKE, N., CONERY, A. L., SHEN, S., PAN, W., LEE, K., RAJAMUTHIAH, R., FUCHS, B. B., VlAHOVSKA, P. M., WUEST, W. M., GILMORE, M. S., GAO, H., AUSUBEL, F. M. \& MYLONAKIS, E. 2018. A new class of synthetic retinoid antibiotics effective against bacterial persisters. Nature, 556, 103-107.

LEE, D. S., QIAN, H., TAY, C. Y. \& LEONG, D. T. 2016. Cellular processing and destinies of artificial DNA nanostructures. Chem Soc Rev, 45, 4199-225.

LeE, H., LytTOn-JeAn, A. K. R., Chen, Y., LOVE, K. T., PARK, A. I., KARAGiannis, E. D., SEHGAL, A., QUERBES, W., ZURENKO, C. S., JAYARAMAN, M., PENG, C. G., CHARISSE, K., BORODOVSKY, A., MANOHARAN, M., DONAHOE, J. S., TRUELOVE, J., NAHRENDORF, M., LANGER, R. \& ANDERSON, D. G. 2012. Molecularly self-assembled nucleic acid nanoparticles for targeted in vivo siRNA delivery. Nature nanotechnology, 7, 389-93.

LINKO, V., ORA, A. \& KOSTIAINEN, M. A. 2015. DNA Nanostructures as Smart Drug-Delivery Vehicles and Molecular Devices. Trends in biotechnology, 33, 586-594.

MENG, J., HE, G., WANG, H., JIA, M., MA, X., DA, F., WANG, N., HOU, Z., XUE, X., LI, M., ZHOU, Y. \& LUO, X. 2015. Reversion of antibiotic resistance by inhibiting mecA in clinical methicillin-resistant Staphylococci by antisense phosphorothioate oligonucleotide. The Journal of antibiotics, 68, 158-64.

READMAN, J. B., DICKSON, G. \& COLDHAM, N. G. 2017. Tetrahedral DNA Nanoparticle Vector for Intracellular Delivery of Targeted Peptide Nucleic Acid Antisense Agents to Restore Antibiotic Sensitivity in Cefotaxime-Resistant Escherichia coli. Nucleic acid therapeutics,27, 176-181.

ROWNICKI, M., WOJCIECHOWSKA, M., WIERZBA, A. J., CZARNECKI, J., BARTOSIK, D., GRYKO, D. \& TRYLSKA, J. 2017. Vitamin B12 as a carrier of peptide nucleic acid (PNA) into bacterial cells. Scientific reports, 7, 7644.

SETYAWATI, M. I., KUTTY, R. V., TAY, C. Y., YUAN, X., XIE, J. P. \& LEONG, D. T. 2014. Novel Theranostic DNA Nanoscaffolds for the Simultaneous Detection and Killing of Escherichia coli and Staphylococcus aureus. Acs Applied Materials $\&$ Interfaces,6, 21822-21831. 
WALSH, A. S., YIN, H., ERBEN, C. M., WOOD, M. J. A. \& TURBERFIELD, A. J. 2011. DNA cage delivery to mammalian cells. ACS nano, $5,5427-32$.

XIA, Z., WANG, P., LIU, X., LIU, T., YAN, Y., YAN, J., ZHONG, J., SUN, G. \& HE, D. 2016. TumorPenetrating Peptide-Modified DNA Tetrahedron for Targeting Drug Delivery. Biochemistry, 55, 1326-31.

ZHANG, Y., MA, W., ZHU, Y., SHI, S., LI, Q., MAO, C., ZHAO, D., ZHAN, Y., SHI, J., LI, W., WANG, L., FAN, C. \& LIN, Y. 2018. Inhibiting Methicillin-Resistant Staphylococcus aureus by Tetrahedral DNA Nanostructure-Enabled Antisense Peptide Nucleic Acid Delivery.Nano letters .

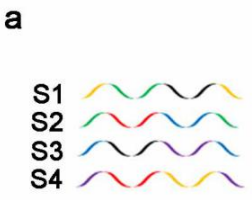

c

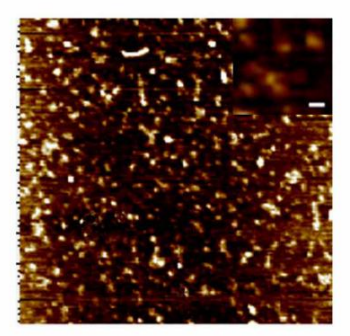

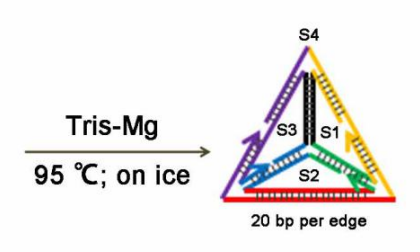

d $\begin{array}{lllll}\text { b } & 1 & 2 & 3 & 4\end{array}$

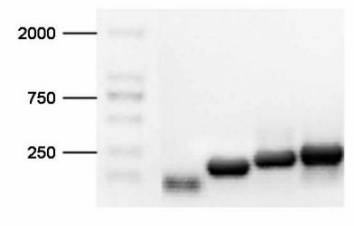

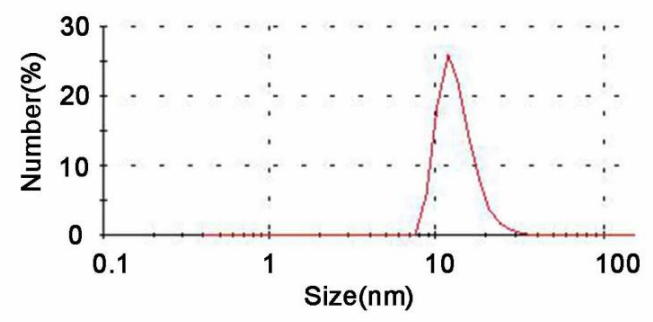

Figure 1. Characteristics of the Td. a) A sketch of Td self-assembly. b) Agarose gel of single-strand DNA, partial assembly, and Td. Lane 1: S1; Lane 2: S1+S2; Lane 3: S1+S2+S3; Lane 4: S1+S2+S3+S4. c) AFM images of Td showing its triangle-like shape. The scale bar is $10 \mathrm{~nm}$. d) The hydrodynamic size of Td determined by DLS analysis. 

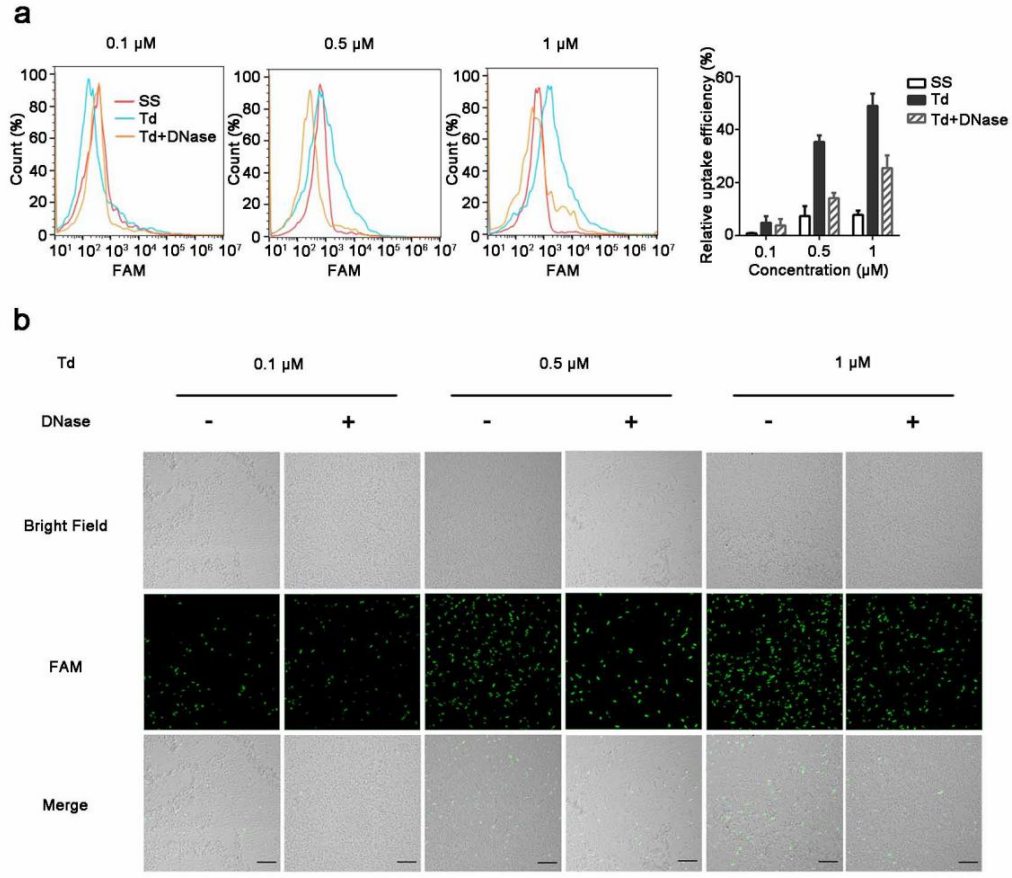

Figure 2. Td uptake by $\boldsymbol{E}$. coli. a) Flow cytometry and b) confocal microscopy imaging to analyze the uptake efficiency of $\mathrm{Td}$ by $E$. coli. The bacterial cells were incubated with different concentrations of FAM-labeled $\mathrm{Td}(0.1,0.5$, or $1 \mu \mathrm{M})$ for $1.5 \mathrm{~h}$ and then were either treated or not treated with DNase before flow cytometry and confocal microscopy analyses. SS: single-strand DNA; Td: DNA tetrahedron. SS was used as a control. Scale bars represent $10 \mu \mathrm{m}$.

a

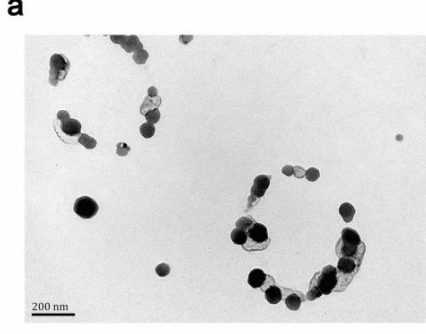

C

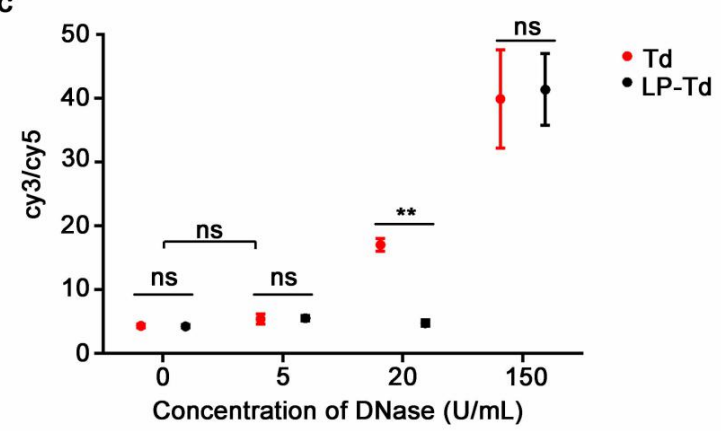

b

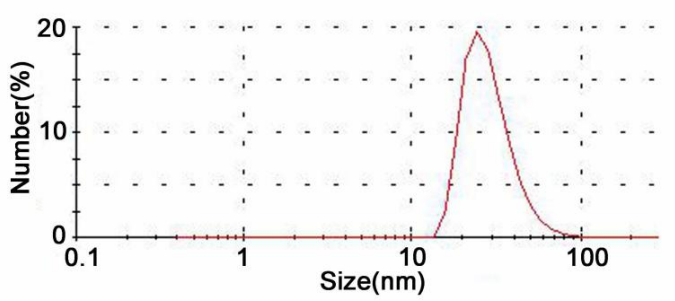


Figure 3. Characteristics and stability of the LP-Td. a) TEM images of LP-Td. The scale bar is $200 \mathrm{~nm}$. b) The hydrodynamic size of LP-Td determined by DLS analysis. c) Enzymatic stability of Td and LP-Td. $0.2 \mu \mathrm{M}$ cy3/cy5 doubly labeled Td or LP-Td were incubated with DNase in different concentrations for 15 min. "ns": no significance; “**": $p$ ¡0.01.

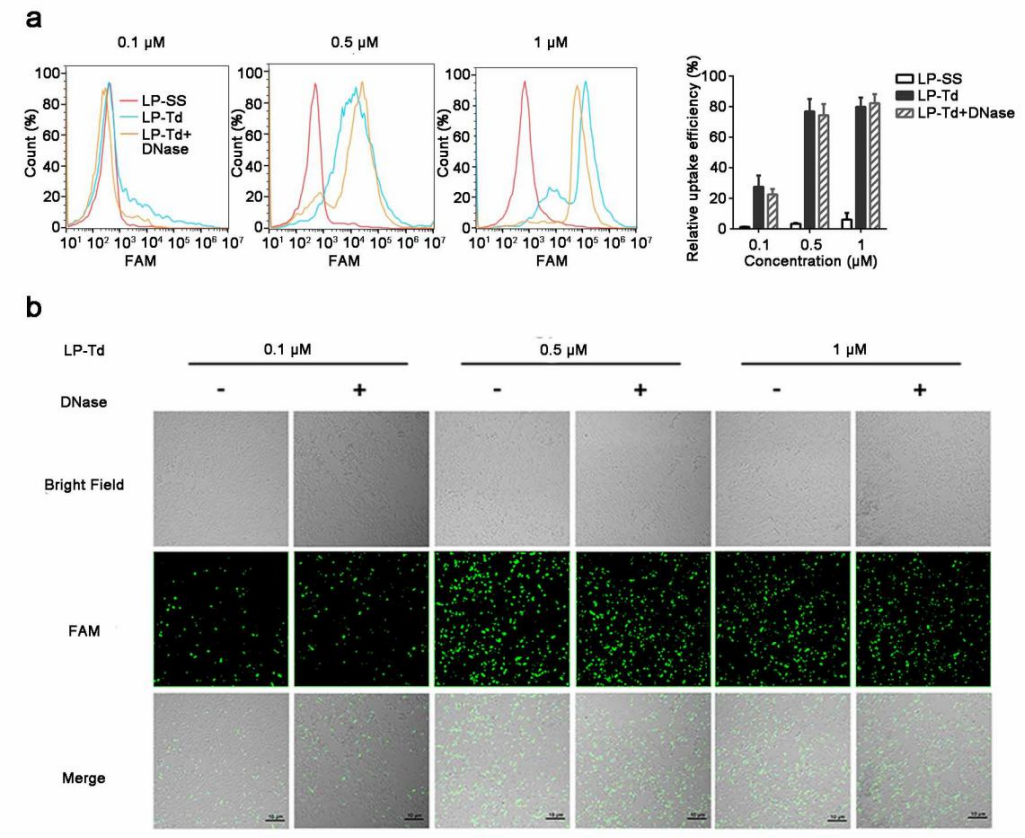

Figure 4. Td uptake by $E$. coli with the help of LP2000.a) Flow cytometry and b) confocal microscopy imaging to analyze the uptake efficiency of Td mixed with LP2000 (LP-Td) by E. coli. The bacterial cells were incubated with different concentrations of FAM-labeled LP-Td $(0.1,0.5$, or $1 \mu \mathrm{M})$ for 1.5 $\mathrm{h}$ and then either treated or not treated with DNase before flow cytometry and confocal microscopy analyses. The LP2000/Td ratio was $0.125 \mu \mathrm{L} / \mu \mathrm{g}$. SS: single-strand DNA; Td: DNA tetrahedron; LP: LP2000. SS was used as a control. Scale bars represent $10 \mu \mathrm{m}$. 
a

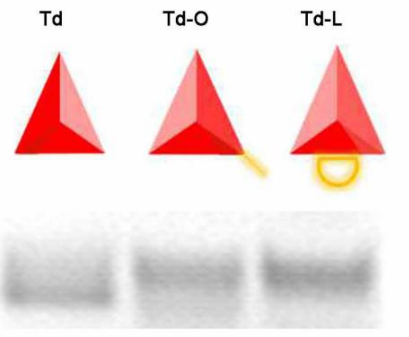

b

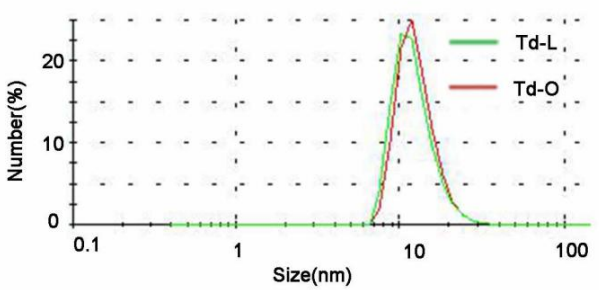

C
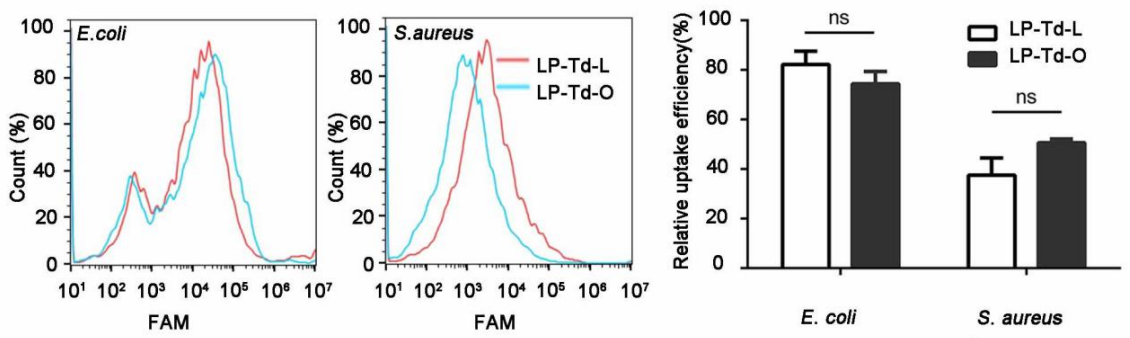

Figure 5. Characteristics and uptake efficiency of Td carrying ASOs. a) A sketch of Td-O and Td-L and the formation of Td-O and Td-L verified by agarose gel. b) The hydrodynamic size of Td-O and Td-L determined by DLS analysis. c) Flow cytometry analysis of the uptake efficiency of LP-Td-O and LP-Td-L by $E$. coli and $S$. aureus. The bacterial cells were incubated with $0.5 \mu \mathrm{M}$ FAM-labeled LP-Td-L or LP-TD-O for $1.5 \mathrm{~h}$ and then assessed by flow cytometry. LP: LP2000. 


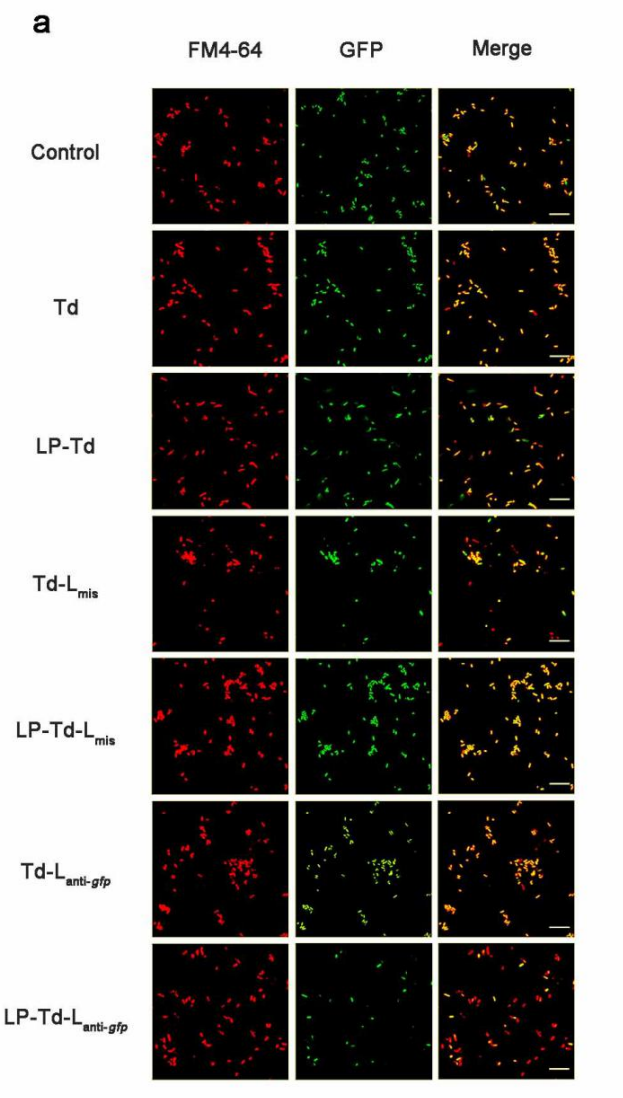

b

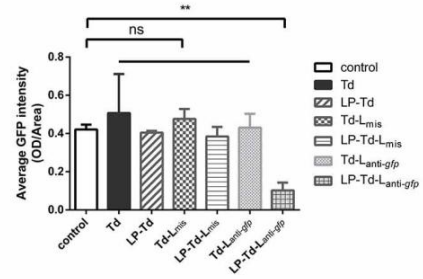

C
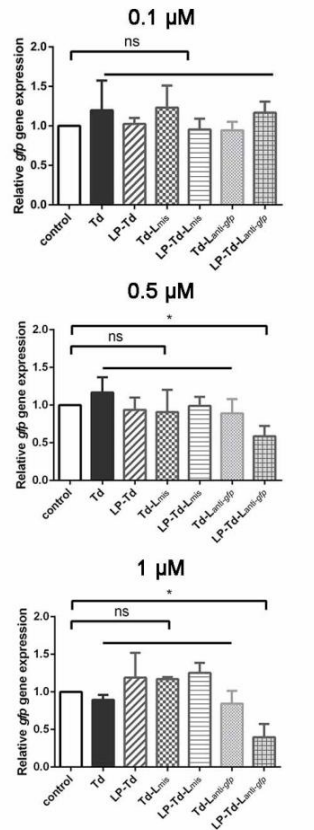

Figure 6. Gene-inhibiting efficiency of LP-Td-L targeting $g f p$ in E. coli expressing GFP. a) Confocal microscopy imaging to investigate GFP fluorescence intensity after treating bacteria with $1 \mu \mathrm{M}$ Td-L anti-gfp with or without LP2000 for $6 \mathrm{~h}$. Red fluorescence was from FM4-64. b) Semiquantitative analysis of GFP fluorescence intensity. c) Quantitative real-time PCR analysis of $g f p$ mRNA levels after exposure to different concentrations of Td- $\mathrm{L}_{\text {anti-gfp }}$ or LP-Td- $\mathrm{L}_{\text {anti-gfp }}(0.1,0.5$, or $1 \mu \mathrm{M})$ for $3 \mathrm{~h}$. Td- $\mathrm{L}_{\text {mis }}$ was used as a negative control to confirm specific gene inhibiting of ASOs. Scale bars represent $10 \mu \mathrm{m}$. "**: $p$ $¡ 0.05 ;$ “**”: $p$ ¡0.01 versus control group. 


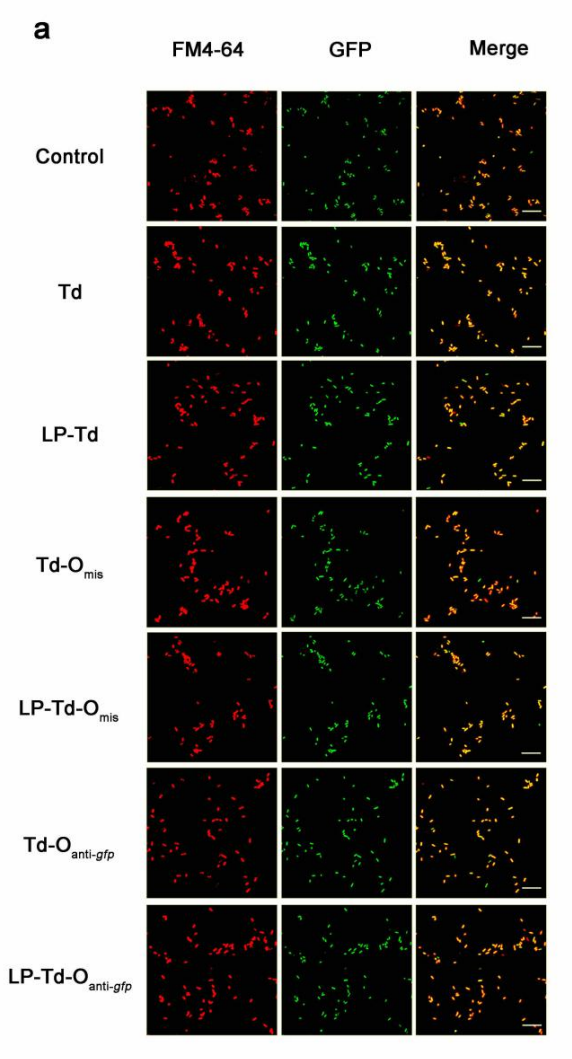

b

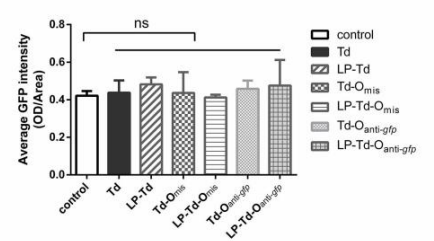

c
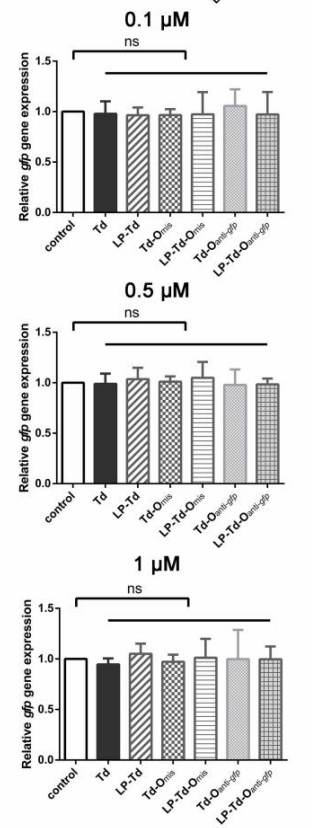

Figure 7. Gene-inhibiting efficiency of LP-Td-O targeting gfp in E. coli expressing GFP. a) Confocal microscopy imaging to investigate GFP fluorescence intensity after treating bacteria with $1 \mu \mathrm{M}$ Td-Oanti-gfp with or without LP2000 for $6 \mathrm{~h}$. Red fluorescence was from FM4-64. b) Semiquantitative analysis of GFP fluorescence intensity. c) Quantitative real-time PCR analysis of $g f p \mathrm{mRNA}$ levels after exposure to different concentrations of Td-O $\mathrm{O}_{\text {anti- } g f p}$ or LP-Td- $\mathrm{O}_{\text {anti- } g f p}(0.1,0.5$, or $1 \mu \mathrm{M})$ for $3 \mathrm{~h}$. Td- $\mathrm{O}_{\text {mis }}$ was used as a negative control to confirm specific gene inhibiting of ASOs. Scale bars represent $10 \mu \mathrm{m}$. "*”: $p$ $¡ 0.05 ; “ * * \cdots: p$ ¡0.01 versus control group.
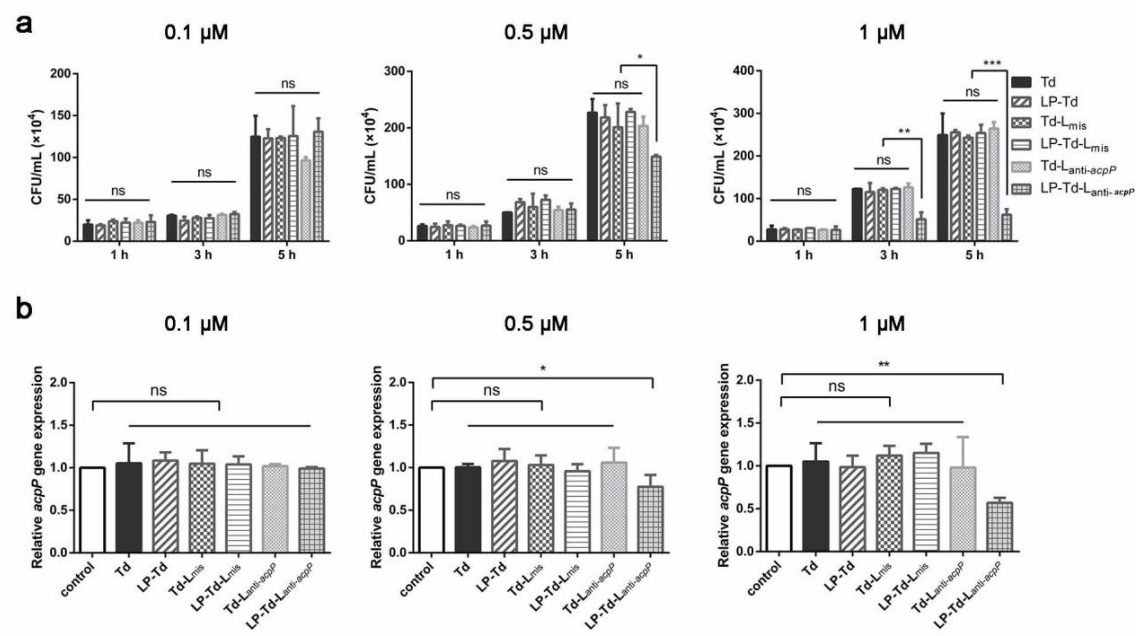
Figure 8. Bacterial growth inhibitory effect of LP-Td-L by inhibiting the acpP gene in $E$. coli. a) Colony counting of $E$. coli after treatment with different concentrations of $T d-L_{\text {anti-acpP }}(0.1,0.5$, or 1 $\mu \mathrm{M})$ with or without LP2000 for different times $(1,3$ or $5 \mathrm{~h}$ ). b) Quantitative real-time PCR analysis of acp $P$ mRNA levels after exposure to different concentrations of Td- $\mathrm{L}_{\text {anti- acpP }}$ or LP-Td- $\mathrm{L}_{\text {anti- } a c p P}(0.1,0.5$, or $1 \mu \mathrm{M}$ ) for $3 \mathrm{~h}$. Td- $\mathrm{L}_{\text {mis }}$ was used as a negative control to confirm specific gene inhibiting of ASOs. "*": $p \nmid 0.05 ; “ * * ": p ; 0.01 ; “ * * * *: p ; 0.001$ versus control group.

Supporting Information

Loop-armed DNA Tetrahedron Nanoparticles for Delivering Antisense Oligos into Bacteria

Yue $\mathrm{Hu}^{+}, 1$, Zhou Chen ${ }^{+,}$, Xinggang $\mathrm{Mao}^{++}{ }^{1}$, Mingkai $\mathrm{Li}^{+}$, Zheng $\mathrm{Hou}^{+}, \mathrm{Jingru}_{\mathrm{Meng}}{ }^{+}$, Xiaoxing $\mathrm{Luo}^{+},{ }^{*}$, Xiaoyan $\mathrm{Xue}^{+, *}$

DNA strands for self-assembly

S1 AGGCAGTTGAGACGAACATTCCTAAGTCTGAAATTTATCACCCGCCATAGTAGACGTATCACC S2 CTTGCTACACGATTCAGACTTAGGAATGTTCGACATGCGAGGGTCCAATACCGACGATTACAG

S3 GGTGATAAAACGTGTAGCAAGCTGTAATCGACGGGAAGAGCATGCCCATCCACTACTATGGCG

S4 CCTCGCATGACTCAACTGCCTGGTGATACGAGGATGGGCATGCTCTTCCCGACGGTATTGGAC

Loop-S1

TTTATCACCCGCCATAGTAGACGTATCACCAGGCAGTTGAGA

Overhang-S1

CGAACATTCCTAAGTCTGAAATTTATCACCCGCCATAGTAGA

Loop $_{\text {anti- } g f p}$

CGAACATTCCTTTACAGCTCCTCGCCCTTCGTTTTAAGTCTGAAA

Overhanganti-gfp

CGTATCACCAGGCAGTTGAGATTTTTTTACAGCTCCTCGCCCTTCG

Loopanti- acp $P$

CGAACATTCCTTTCTTCGATAGTGTTTTAAGTCTGAAA

Overhang $_{\text {anti- } a c p P}$

CGTATCACCAGGCAGTTGAGATTTTTTTCTTCGATAGTG

Loopmis

CGAACATTCCTTTATCGGCCATCGCCATCCGTTTTAAGTCTGAAA

Overhangmis

CGTATCACCAGGCAGTTGAGATTTTTTTATCGGCCATCGCCATCCG

Plasmid profile of pEGFP-LAC

pEGFP-LAC was purchased from Miaolingbio (China). 
a

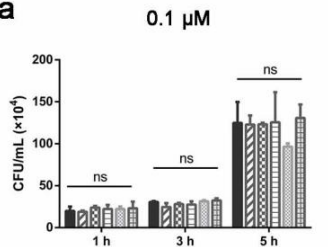

b

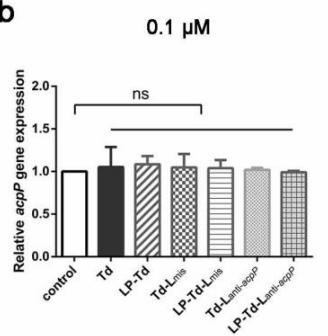

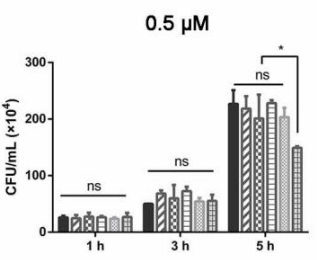
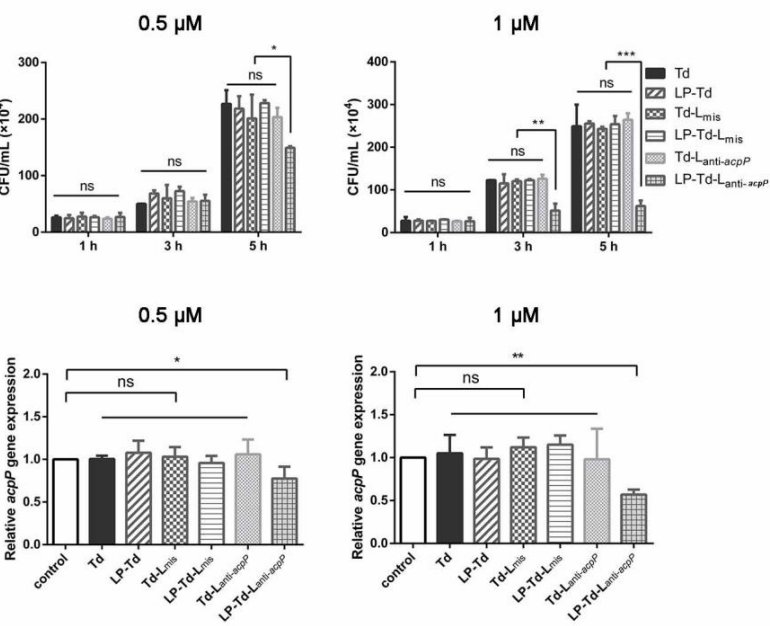

a
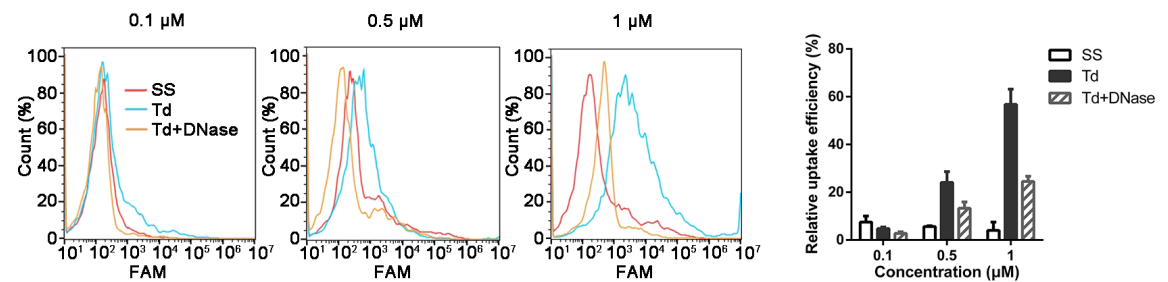

b
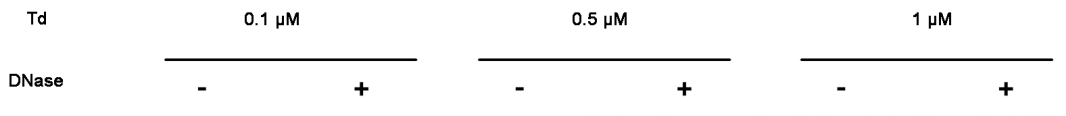

Bright Field
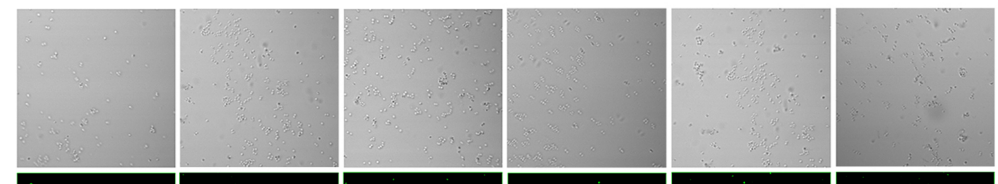

FAM
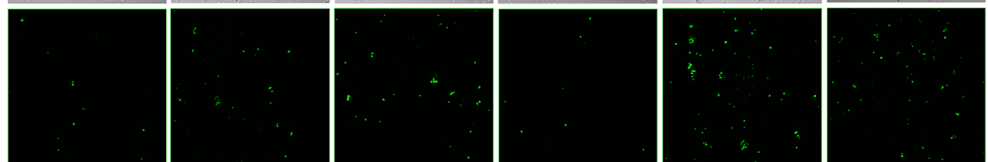

Merge
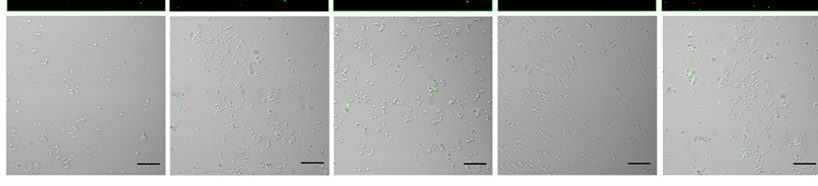

Figure S1. Td uptake by S.aureus. a) Flow cytometry and b) confocal microscopy imaging to analyze the uptake efficiency of Td byS.aureus. The bacterial cells were incubated with different concentrations of FAM-labeled $\mathrm{Td}(0.1,0.5$, or $1 \mu \mathrm{M})$ for $1.5 \mathrm{~h}$ and then were either treated or not treated with DNase before flow cytometry and confocal microscopy analyses. SS: single-strand DNA; Td: DNA tetrahedron. SS was used as a control. Scale bars represent $10 \mu \mathrm{m}$. 


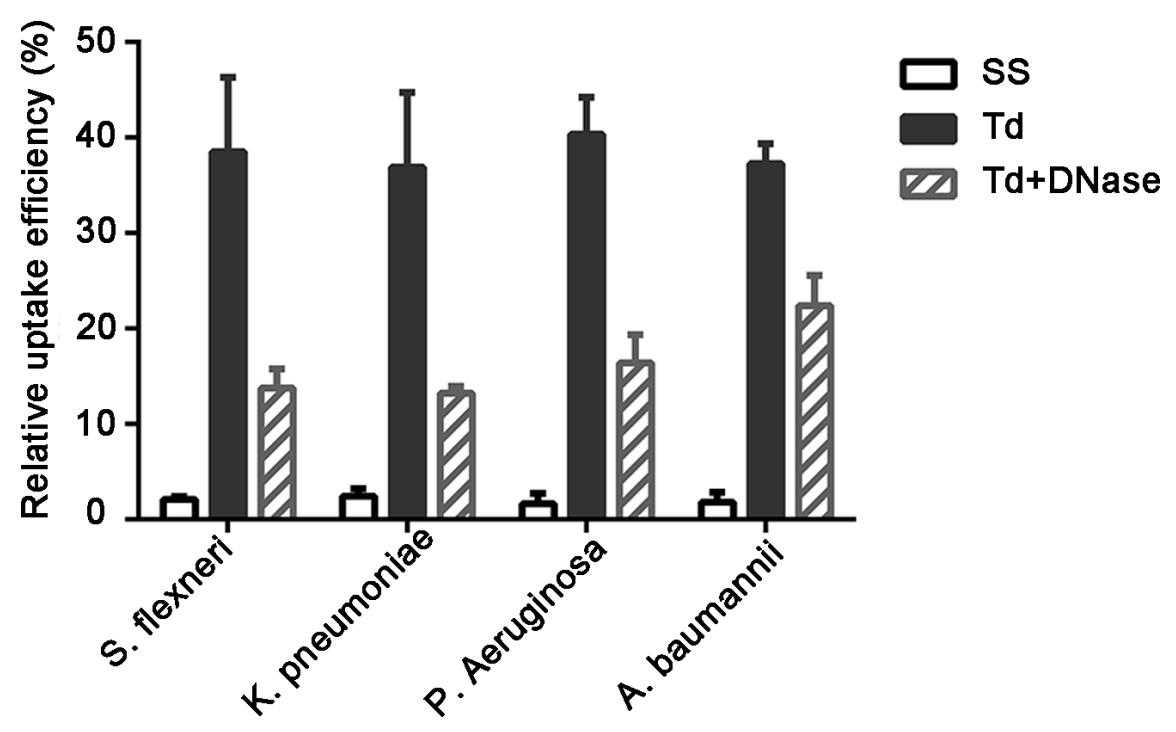

Figure S2. Uptake efficiency of Td in different bacterial strains analyzed by flow cytometry. The bacterial cells were incubated with $\mathrm{Td}(0.5 \mu \mathrm{M})$ for $1.5 \mathrm{~h}$ and then were either treated or not treated with DNase before flow cytometry analysis. SS: single-strand DNA; Td: DNA tetrahedron. SS was used as a control.

a

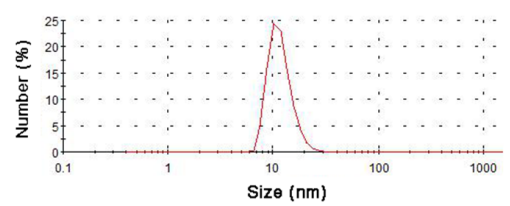

C

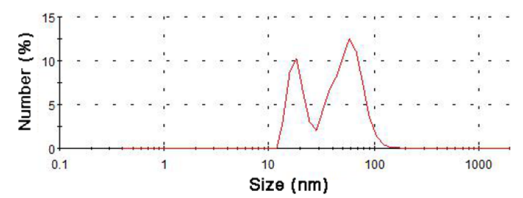

b

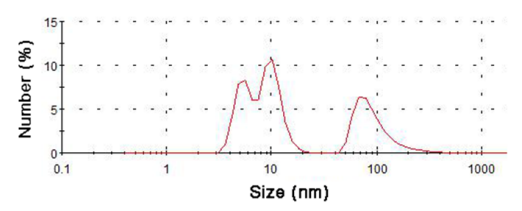

d

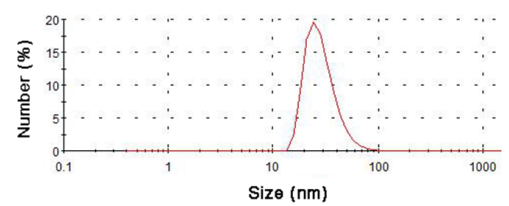

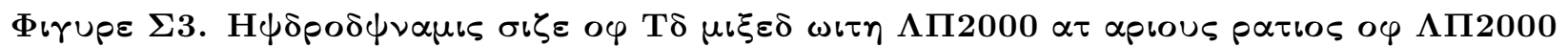

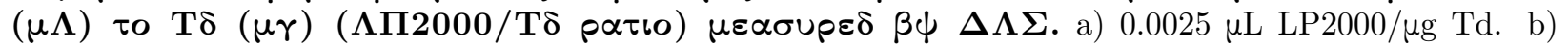
$0.0125 \mu \mathrm{L} \mathrm{LP} 2000 / \mu \mathrm{g}$ Td. c) $0.025 \mathrm{LP} 2000 \mu \mathrm{L} / \mu \mathrm{g}$ Td. d) $0.125 \mu \mathrm{L} \mathrm{LP} 2000 / \mu \mathrm{g}$ Td. 

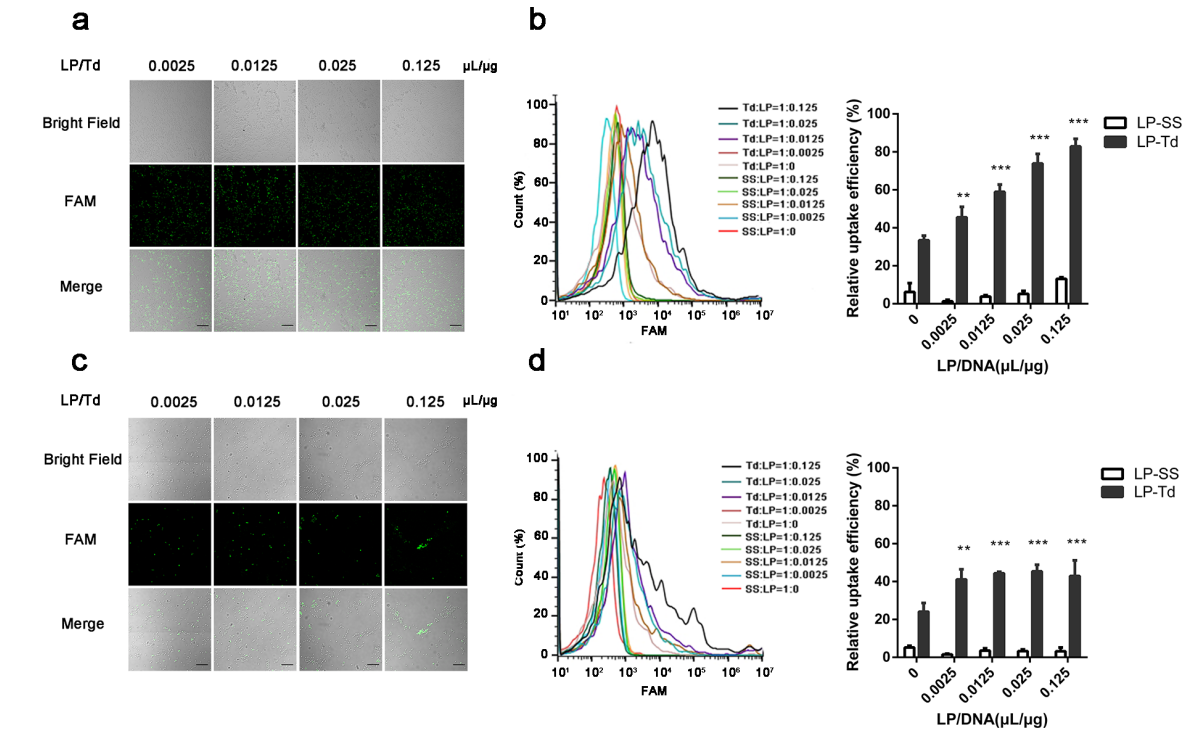

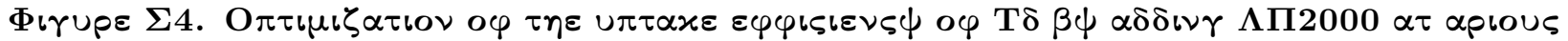

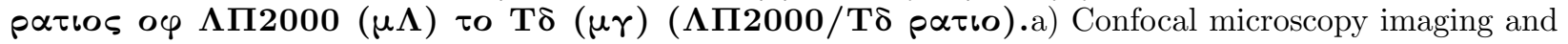
b) flow cytometry to analyze the uptake efficiency of Td at different LP2000/Td ratios $(0.0025,0.0125$, 0.025 , or $0.125 \mu \mathrm{L} / \mu \mathrm{g}$ ) in $E$. coli . c) Confocal microscopy imaging and d) flow cytometry to analyze the uptake efficiency of $\mathrm{Td}$ at different LP2000/Td ratios $(0.0025,0.0125,0.025$, or $0.125 \mu \mathrm{L} / \mu \mathrm{g})$ in $S$. aureus . SS: single-strand DNA; Td: DNA tetrahedron. SS was used as a control. “**”: $p \nmid 0.01 ; “ * * * ": p j 0.001 . \mathrm{P}$ value versus the $0 \mu \mathrm{L} / \mu \mathrm{g}$ group.
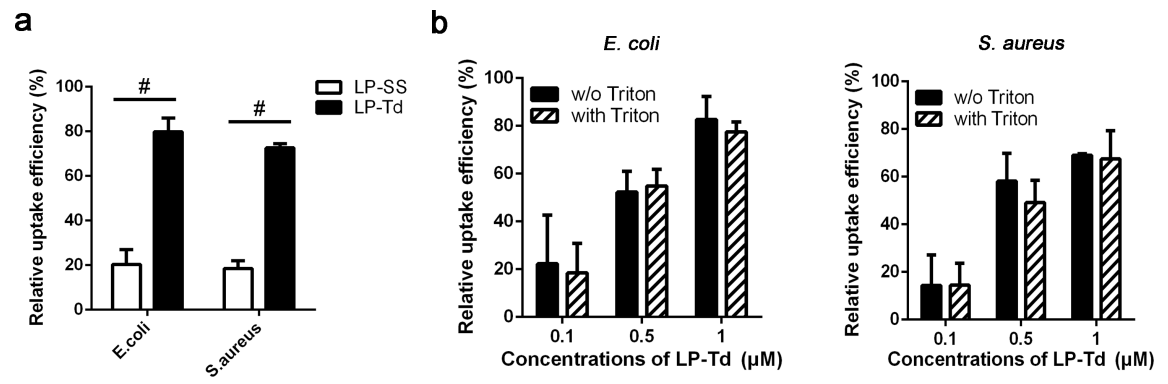

Figure S5. Superiority of Td to cross bacterial membrane with the help of LP2000. a) flow cytometry to analyze the uptake efficiency of single strand DNA or Td $(1 \mu \mathrm{M})$ with the same absolute amount LP2000 ( LP2000/Td ratio was $0.125 \mu \mathrm{L} / \mu \mathrm{g}$ ) in E.coli and $S$. aureus.b) flow cytometry to clarify the influence of Triton X-100 on bacterial uptake efficiency of LP-Td in E.coli and S. aureus . "\#” : $p$ ¡0.0001 
a
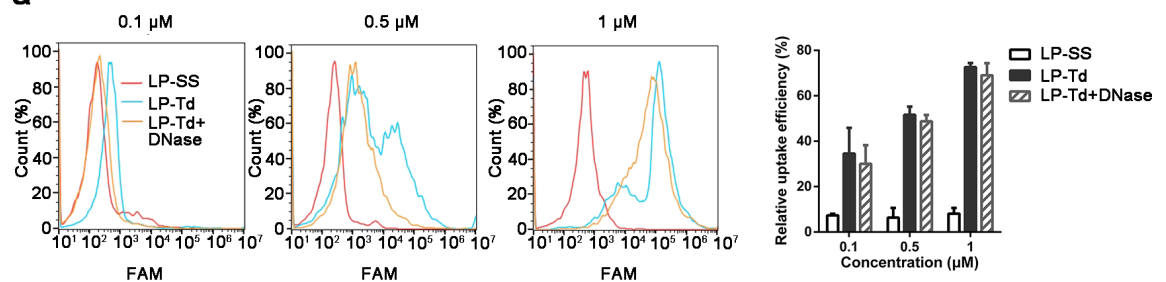

b

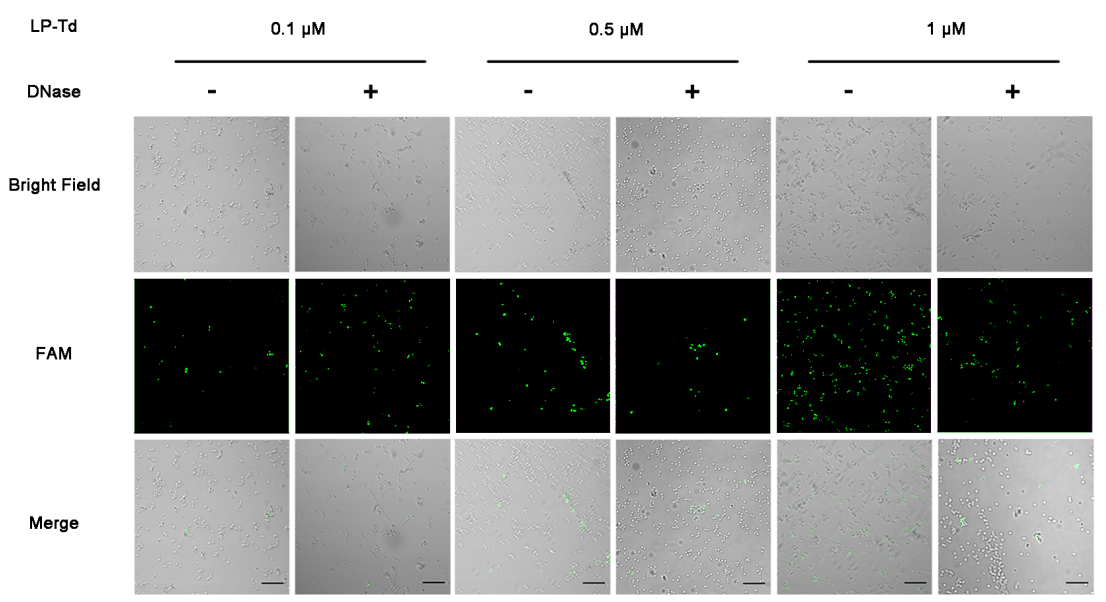

Figure S6. Td uptake by S.aureus with the help of LP2000. a) Flow cytometry and b) confocal microscopy imaging to analyze the uptake efficiency of Td mixed with LP2000 (LP-Td) byS.aureus. The bacterial cells were incubated with different concentrations of FAM-labeled LP-Td $(0.1,0.5$, or $1 \mu \mathrm{M})$ for 1.5 $\mathrm{h}$ and then either treated or not treated with DNase before flow cytometry and confocal microscopy analyses. The LP2000/Td ratio was $0.125 \mu \mathrm{L} / \mu \mathrm{g}$. SS: single-strand DNA; Td: DNA tetrahedron; LP: LP2000. SS was used as a control. Scale bars represent $10 \mu \mathrm{m}$.

a

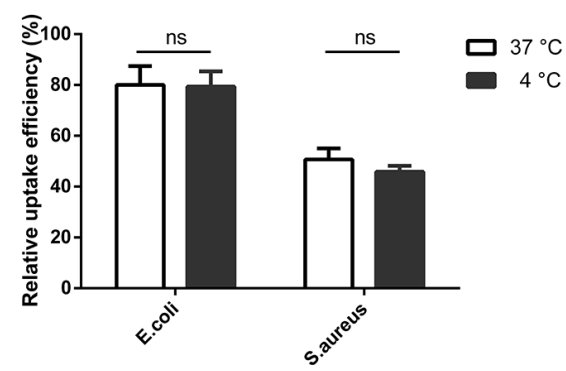

b

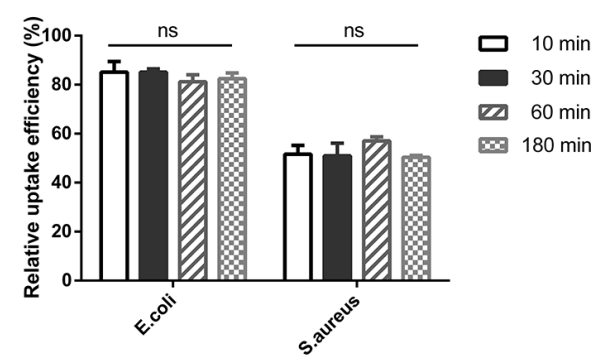

Figure S7. The influence of temperature and time on bacterial uptake rates of LP-Td. Bacteria were incubated with $\mathrm{Td}(0.5 \mu \mathrm{M})$ for $1.5 \mathrm{~h}$. ns: no significance. 

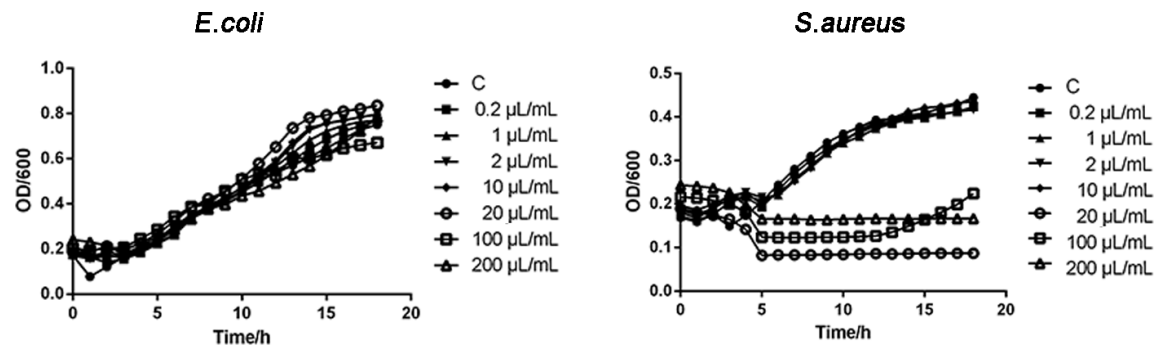

Figure S8. Bacterial toxicity of LP2000. Bacteria were treated with LP2000 at different concentrations, and a growth assay was conducted for $18 \mathrm{~h}$.
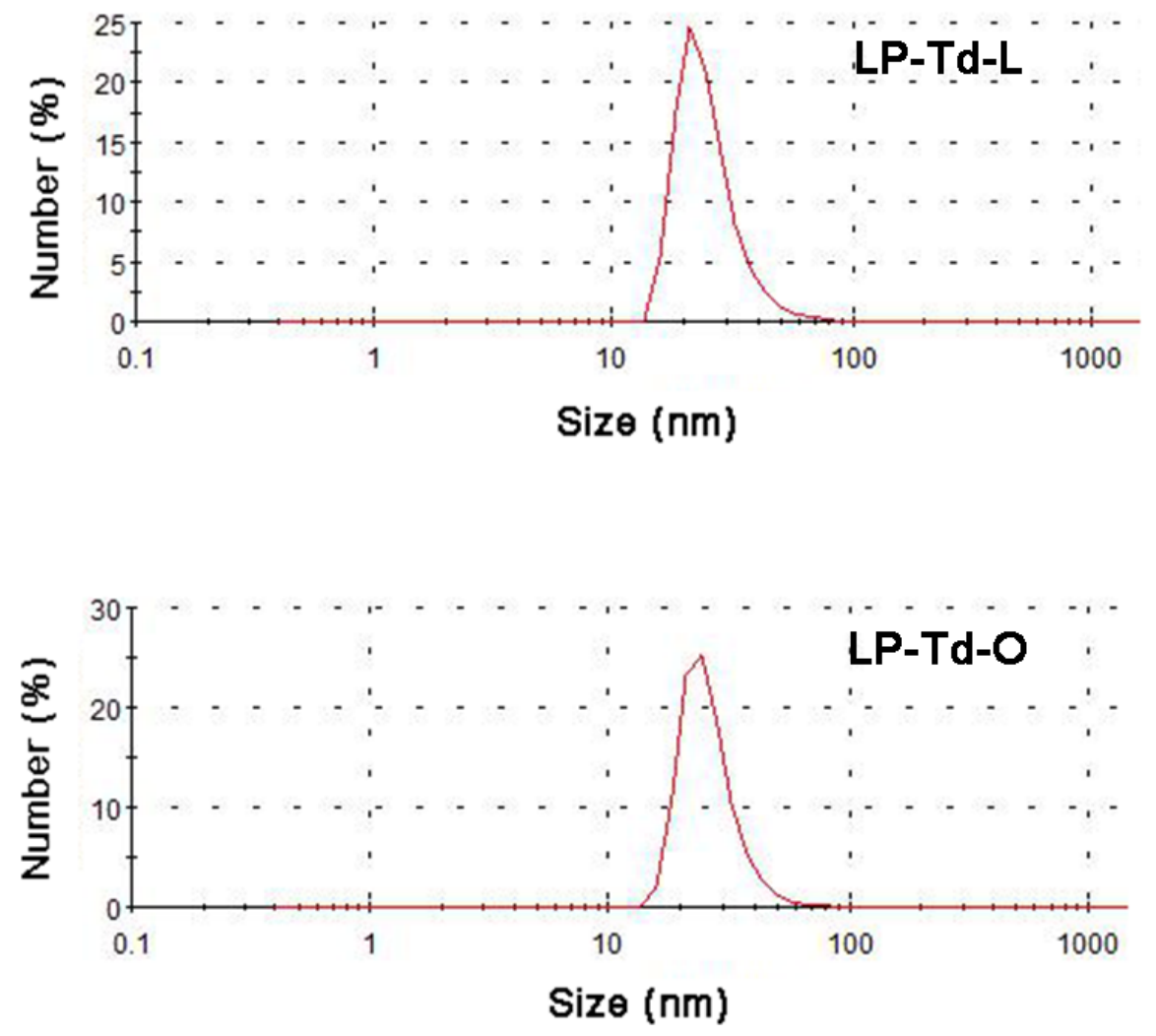

Figure S9. Hydrodynamic size of LP-Td-O and LP-Tsd-L measured by DLS. The LP2000/Td ratio was $0.125 \mu \mathrm{L} / \mu \mathrm{g}$. 